\title{
Knowledge sharing, visibility improvement and productivity growth: Evidence from agro- industry manufacturing firm
}

\author{
Kevin Natalardo ${ }^{1}$ and Oki Sunardi ${ }^{1, \mathrm{a}}$ \\ ${ }^{1}$ Department of Industrial Engineering, Krida Wacana Christian University, 11470 Jakarta, Indonesia
}

\begin{abstract}
During the last five years, agro-industry has become national largest workforce absorption sector, in which 38.3 million to 48.5 million people work in this area. However, in average, the productivity level of workforce in agro-industry sector is considered to be the most alarming. This study aims to uncover the best practice on how to enhance the productivity growth within a leading Indonesian agro-industry manufacturing firm. Survey to 46 respondents confirms that knowledge sharing practice and visibility improvement have proven to be significantly positive to affecting the productivity growth within the firm.
\end{abstract}

\section{Introduction}

Indonesia was positioned at the fifth place behind Singapore, Malaysia, Thailland and the Philippines, in term of workforce productivity level amongst ASEAN countries in 2017. In regards with nation's competitiveness level, Indonesia was ranked $42^{\text {nd }}$ (leveraged six level from $48^{\text {th }}$ in 2016) [https://www.imd.org]. The increasing level of Indonesia competitiveness is parallel with the increasing of human capital index, which measures how countries are improving and organizing their workforce and follow their improvement over time. In term of Human Capital Index, Indonesia was ranked $65^{\text {th }}$ in 2017 , compared to $69^{\text {th }}$ in 2015 [https://www.weforum.org]. In similar, better workforce productivity level was also concurrent with the increase of nation's economic growth by 5.06 percent during the last quarter of 2017, compared to 5.02 percent in 2016 [http://bisnis.liputan6.com, 06 Nov 2017].

Agricultural industry (agro-industry) is one of the largest contributor to nation's economic growth, second to the food and beverage industry. According to the Indonesian Central Bureau of Statistics (BPS), during the 2012-2017, the agro-industry sector has continued to contribute positively to the Indonesian economy. During the same period, the agro-industry sector has also been the largest workforce absorption sector, in which 38.3 million to 42.5 million people working in this sector. In other words, the agro-industry

\footnotetext{
*Corresponding author: oki.sunardi@ukrida.ac.id
} 
sector has become the driving force of the national economy. However, the productivity level of the agro-industry sector is considered the lowest compared to other sectors, since only a number of firms have shown the growing productivity trends [http://bps.go.id]. This condition has become one of the intriguing concerns for the Indonesian government, since agro-industry sector is considered as one of the most workforce intensive sectors in Indonesia.

IMD World Competitiveness Center reports in the early 2018 that the lack of knowledge transfer and underutilized human capital development programs have been identified as the main causes of the declining of the productivity level of some of the growing Asian countries, especially the workforce intensive sectors, if compared to the European and well-developed countries in Asia (Japan, Korea, Singapore and Hong Kong). Productivity concern is still dominant because many employers in growing Asian countries still consider human productivity as a result of specialization of human skill, rather than the believe that human productivity and creativity are the outcomes of knowledge transfer and talent recognition by the employers to the workforce [https:/www.imd.org]. In fact, previous studies in various field found that many workforce consider knowledge transfer practice as threats to his/her wellbeing. By transferring knowledge, others may have the opportunity to outpace the job promotions $[1,2]$. In reciprocal perspective, knowledge transfer or knowledge sharing may occur to two or more people when knowledge sharing intention is visible to both parties [3, 4]. People tend to be more open to share information or knowledge when they have a visibility to a concern or issue or effect [5].

This study aims to uncover the factors which drive the productivity growth within the agro-industry manufacturing firm. The structure of this paper is constructed as follow. First, theoretical model and hypothesis are developed by examining the relationship between knowledge transfer practice and productivity growth, as well as visibility improvement and productivity growth. Second, the model is then tested through single case study. The final part of this paper incorporates conclusion and suggestion for further study.

\section{Literature review}

Previous studies have examined the effects of knowledge management practices (e.g. knowledge acquisition, knowledge sharing, knowledge storage, knowledge creation, and knowledge implementation) on organizational productivity. Fostering knowledge sharing practices can be an important role to increasing productivity, financial performance, staff performance, innovation, and working relationships [6]. Self-concept, knowledge sharing, and knowledge utilization have shown an important role in improving the productivity of employees over time [7].

Studies in agro-industry which examine the role of knowledge sharing to productivity growth were limited in number. The Organization for Economic Co-operation and Development (OECD) suggested that productivity growth in agro-industry could be leveraged through improving trade policies, greater investment in agriculture, and economic stability [http://www.oecd.org]. This analysis, however, beyond the capability and authority of a firm. Based on this condition, the first hypotheses can be derived as follow: H1: Knowledge sharing has a significant positive effect on productivity growth.

In terms of visibility, previous study in manufacturing context showed that visibility improvement during the supply chain process has managed to improving performance in terms of operating efficiency, planning effectiveness, and increasing resource productivity [8]. By increasing visibility in the shop floor through good layout design, workforce are more eager to interact with each other, increasing the likelihood of teamwork and producing higher productivity [9]. Thus, the second hypotheses is developed as follow: $\mathrm{H2}$ : Visibility improvement has a significant positive effect on productivity growth. 


\subsection{Knowledge sharing}

Knowledge sharing is a method of sharing knowledge or idea or positive information among members within an organization or company. The more knowledge the people possess, the more they continue to do something or to solve problems in effective ways [10]. Some factors that were proven to support knowledge sharing can be in the form of attitude [1], organizational culture [11], effective reward system [12], and empowering leadership [12].

Attitude can be described as the behaviour of a person in interacting or communicating with others. Attitude displayed by the workforce illustrates how the company will be maintained and managed. It is believed that attitude has an influence on behavioural intention toward knowledge sharing [10]. Individuals' feelings about knowledge sharing reflect their own readiness to engage with improvement and productivity. The following hypotheses can be formulated as follow: Hla: Attitude has a significant positive effect on knowledge sharing.

Organizational culture is a characteristic as well as values that are upheld by the organization and become examples of organizations to differentiate with other organizations. Behaviour in organizations is more determined by the culture than the direction of senior management [11]. Workforce are generally motivated to gather knowledge to maintain their competitive advantage. Thus, if the organizational culture can be infused towards knowledge sharing culture, then it is expected to accumulate knowledge from time to time. The following hypotheses can be derived as follow: H1b: Organizational culture has a significant positive effect on knowledge sharing.

Assessment on performance or rewards system must be practical, significant, and open to encourage knowledge sharing activities within an enterprise [12]. Rewards system aims to retain workforce with good performance from other companies' intention to recruit, and to motivate workforce to work harder. Some large companies explicitly show in employee performance indicators to acquire, store, distribute and apply knowledge that are linked to rewards system. The next hypotheses can be formulated as follow: H1c: Effective reward system has a significant positive effect on knowledge sharing.

Empowering leadership can be described as the process that enable workforce to feel meaningful with their work, provides autonomy and confidence during works, and remove obstacles in decision making. The main component of empowering leadership is to empower teams to work together and encourage team members to develop selfmanagement or leadership skills so as to improve employee performance. The coaching behaviour of the empowering leader will also help members among teams to solve problems together, and therefore, provide an opportunity to share knowledge [12]. The following hypotheses can be formulated into: H1d: Empowering leadership has a significant positive effect on knowledge sharing.

\subsection{Visibility improvement}

Because workforce perceive expertise, skills, knowledge and new ideas as the sources of competitive advantages, they sometimes reluctant to share with others [2]. This implies that individuals will be reluctant to share if the exchange does not benefit them [4]. Visibility can be understood as every aspect of the work process that affects the outcome, and therefore, it should be visible and known to everyone involved in the process. Increase in visibility can be fostered by relationships [13], affective commitment [14], and policy [15]. Strong relationship is a highly desirable state to implement knowledge sharing, and it is easier to share information based on the existing trust during relationships [15]. Collegial relationships are also expected to create mutual openness among workforce and should ultimately increase productivity growth. The following hypotheses is formulated as follow: H2a: Relationship has a significant positive effect on visibility improvement. 
Commitment enables workforce to be more responsible for his work and to work optimally. Affective commitment enables social relationships and helps to appreciate the value of relationships within the organization [14]. This commitment causes workforce to stand on a job because they want it. With this kind of commitment, it is expected that workforce serve the company wholeheartedly and openly to their organisations which ultimately increases visibility $[19,26]$. Organisations with higher visibility is expected to be more productive. The next hypotheses is formulated as follow: H2b: Affective commitment has a significant positive effect on visibility improvement.

Further, company policies provide general guidance and direction for employees to work and conduct in accordance to company's vision and mission. The objectives of a policy is generally aimed to improving the performance and the value of the company [3, 17]. Effective policies were able to create more work efficiency and increase productivity [15]. The following hypotheses can be formulated as follow: H2c: Effective policies has a significant positive effect on visibility improvement. Figure 1 represents the theoretical framework based on the discussion.

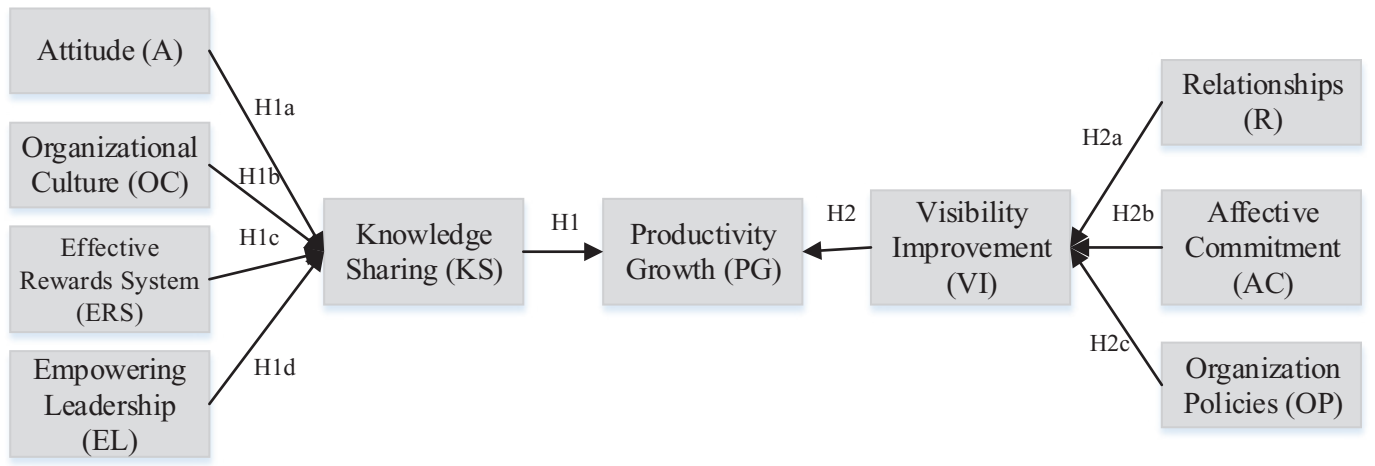

Fig. 1. Theoretical framework.

\section{Methods}

In this study, data were collected from survey to a large-scale agro-industry manufacturing firm in Jakarta, which is considered as one of the most productive and sustainable agroindustry manufacturing firm in Indonesia. The subject is known as the leader in livestock and fisheries-based manufacturer with more than 45 years of experience. By using purposive sampling to 55 employees full time employees with more than one year work experience at the current firm, 46 responds were collected (responds rate at 83.6\%).

Questionnaire is the main instrument in the study with four point scale (e.g. 1: Strongly Agree (SA), 2: Agree (A), 3: Disagree (DS), 4: Strongly Disagree (SDS)). Data were then processed using SmartPLS software. The advantage of SmartPLS is that it can process complex models with many variables and indicators, with the number of samples is between 30 and 100. SmartPLS doesn't require the data normality requirements [18]. In regards with the study, 10 latent variables were employed, which involved 28 manifests. Table 1 describes the variables involved in the study.

Table 1. Variables involved in the study.

\begin{tabular}{|l|l|}
\hline \multicolumn{1}{|c|}{ Latent Variables } & \multicolumn{1}{c|}{ Manifest Variables } \\
\hline Attitude & Self-efficacy, Curiosity, Enjoyment to Assist \\
\hline Organizational Culture & Adaptability, Intention to Detail, Risk Taking to Innovate \\
\hline
\end{tabular}




\begin{tabular}{|l|l|} 
Effective Rewards System & Bonus, Promotion, Acknowledgement \\
\hline Empowering Leadership & $\begin{array}{l}\text { Autonomy, Involvement in Decision Making, Nurturing Self- } \\
\text { confident }\end{array}$ \\
\hline Relationships & Provide Direction, Empathetic Communication, Value Creation \\
\hline Affective Commitment & Providing Work Satisfaction, Providing Growth Opportunity \\
\hline Policy & Bureaucracy, Disposition, Communication \\
\hline Knowledge Sharing & Social Interaction, Trust, Reciprocity \\
\hline Visibility Improvement & Transparency, Accessibility \\
\hline Productivity Growth & Process Efficiency, Skill Development, Work Output \\
\hline
\end{tabular}

\section{Results and discussion}

For validity, convergent validity is used. An indicator is considered to have a high degree of validity when the loading factor value is above 0.5 [20]. Nine statements (of 41) with loading factor values less than 0.5 were excluded from the questionnaire. For reliability, analysis on outer model is used to measure the internal consistency of the indicators. Internal consistency reliability value is set with minimum value of composite reliability at $0.70[19,20]$. Based on the test results, all values of composite reliability are already above 0.70 , so it can be concluded that the model has met the criteria of reliability and is considered as a reliable measuring tool. Table 2 summarizes the values of composite reliability test.

Table 2. Composite reliability values.

\begin{tabular}{|l|c|c|c|c|c|c|c|c|c|c|}
\hline Latent Variables & $\mathrm{A}$ & $\mathrm{AC}$ & $\mathrm{EL}$ & $\mathrm{ERS}$ & $\mathrm{KS}$ & $\mathrm{OC}$ & $\mathrm{OP}$ & $\mathrm{PG}$ & $\mathrm{R}$ & $\mathrm{VI}$ \\
\hline Composite Reliability & 0.81 & 0.82 & 0.87 & 0.80 & 0.74 & 1.00 & 0.83 & 0.78 & 0.76 & 0.83 \\
\hline
\end{tabular}

Coefficient of determinant refers to the R-square value $\left(\mathrm{R}^{2}\right)$ as a measure of how high the influence of independent variables and dependent variables. The greater the value of $\mathrm{R}^{2}$, the greater the effect. The $\mathrm{R}^{2}$ values obtained from the data if the results are as shown in Table 3:

Table 3. Composite reliability values.

\begin{tabular}{|l|c|c|c|}
\hline Dependent Variables & KS & VI & PG \\
\hline R2 & 0.247 & 0.318 & 0.300 \\
\hline
\end{tabular}

Table 3 shows that variables such as attitude, organizational culture, effective reward system, and empowering leadership have effects to knowledge sharing by $24.7 \%$. It means that knowledge sharing practice is $75.3 \%$ influenced by other factors. In other words, possible external factors should not be taken for granted in the success of knowledge sharing, such as commitment of stakeholders, climate for performance, and learning culture $[22,23,24]$.

Variables such as relationship, affective commitment, and organization policy affect the visibility improvement variables by $31.8 \%$, while the other $68.2 \%$ is influenced by other factors. Knowledge sharing and visibility improvement have effect on productivity growth by $30 \%$, while the other $70 \%$ is influenced by other factors which are not examined in this study. In this case, other external factors such as reduction in the rate of capital deepening [25], workforce supply capacities [26], and embodied technical progress [27] could be broader examined. 
The hypothesis testing indicates that, each hypotheses has a positive original sample value, which means that the whole direction of the hypothetical relationship is positive. Level of significance used is 0.05 with t-statistic at 1.69. Table 4 summarized the hypothesis testing results.

Table 4. Hypothesis testing results.

\begin{tabular}{|l|c|c|c|}
\hline \multicolumn{1}{|c|}{ Hypotheses } & t-statistic & t-table & Significance \\
\hline H1: Knowledge Sharing $\rightarrow$ Productivity Growth & 4,228 & 1,69 & Supported \\
\hline H1a: Attitude $\rightarrow$ Knowledge Sharing. & 1,462 & 1,69 & Not Supported \\
\hline H1b: Organizational Culture $\rightarrow$ Knowledge Sharing. & 1,817 & 1,69 & Supported \\
\hline H1c: Effective Reward System $\rightarrow$ Knowledge Sharing. & 0,503 & 1,69 & Not Supported \\
\hline H1d: Empowering Leadership $\rightarrow$ Knowledge Sharing. & 1,459 & 1,69 & Not Supported \\
\hline H2: Visibility Improvement $\rightarrow$ Productivity Growth & 1,992 & 1,69 & Supported \\
\hline H2a: Relationship $\rightarrow$ Visibility Improvement & 4,584 & 1,69 & Supported \\
\hline H2b : Affective Commitment $\rightarrow$ Visibility Improvement & 1,737 & 1,69 & Supported \\
\hline H2c : Policy $\rightarrow$ Visibility Improvement & 0,277 & 1,69 & Not Supported \\
\hline
\end{tabular}

\section{Conclusion}

This case study leads to several findings. First, Attitude, Organizational Culture, Effective Reward System and Empowering Leadership have a positive influence on Knowledge Sharing practice. However, only Organizational Culture has significant influence to boost Knowledge Sharing practice within the organization. Second, Relationship, Affective Commitment, and Organization Policy have a positive influence on Visibility Improvement, but only Relationship and Affective Commitment have significant influence to increase visibility amongst employees during working process. Third, Knowledge Sharing and Visibility Improvement has a role in supporting Productivity Growth, and both are proven to leverage the Productivity Growth within the firm during these years. The findings support the previous study which argues that knowledge sharing has a significant effect on worker productivity [21]. However, the previous study focused on worker productivity, instead of relating whether the productivity had growth over time.

For further research, other external factors, which were not discussed in this study, could also be examined in relation with knowledge sharing (75.3\%), visibility improvement (68.2\%), and productivity growth (70\%). Thorough literature review should be conducted and the subjects of the study should be broaden.

\section{References}

1. A. Jolaee, K. M. Nor, N. Khani, R. M. Yusoff, Int. J. Edu. Manag. 28, 413 (2013)

2. H. S. Lee, S. A. Hong, Osong Public Health Res. Perspect. 5, 148 (2014)

3. O. Sunardi, IOP Conf. Ser.: Mater. Sci. Eng. 277 (2017)

4. O. Sunardi, J. H. Tjakraatmadja, Y. R. Bangun, Int. J. Knowl. Manag. Studies 6, 123 (2015)

5. A. Maghsoudi, A. Pazirandeh, Supply Chain Manag. 21, 125 (2016) 
6. M.H. Gholami, M. N. Asli, S. N. Shirkouhi, A. Noruzy, Acta Polytech. Hung. 10, 205 (2013)

7. S. Okonedo, S. O. Popoola, Library Philosophy \& Practice 865 (2012)

8. M. Caridi, L. Crippa, A. Perego, A. Sianesi, A. Tumino, Bench. An Int. J. 17, 593 (2010)

9. H. M. Chaboki, F. A. A. Wahab, M. Ansari, J. Bus. Manag. 7, 82 (2013)

10. I. Nonaka, The Institute of Manag. Sci. 5, 14 (1994)

11. V. Suppiah, M.S. Sandhu, J. Knowl. Manag. 15, 462 (2011)

12. U. C. Eze, G. G. G. Goh, C. Y. Goh, T. L. Tan, J. Info. Know. Manag. Syst. 43, 210 (2013)

13. P. A. Bartlett, D. M. Julien, T.S. Baines, Int. J. Logist. Manag. 18, 294 (2007)

14. M. K Muchiri, O.B. Ayoko, Lead. Org. Dev. J. 34, 384 (2013)

15. Z. Dickinson, M. Smit, Aslib J. Info. Manag. 68, 589 (2016)

16. A. M. Alsiewi, S. O. S. Agil, J. Bus. Manag. 16, 37 (2014)

17. B. Sudiyanto, E. Puspitasari, A. Kartika, American Int. J. Contemp. Res. 2, 30 (2012)

18. K. Kwong, K. Wong, Mark. Bul. 24, 1 (2013)

19. V. Stefany, O. Sunardi, J. Manajemen Teknologi 13, 322 (2014)

20. S. Alfidella, D.S. Kusumo, D.D.S. Jatmiko, E-Proc. Eng. 2, 1747 (2015)

21. S. M. Saeed, J. Res. Dev. Manag. 21, 16 (2016)

22. C.N.Y. Tan, American J.Econ. and Bus. Adm. 3, 73 (2011)

23. L. Cardoso, A. Meireles, C.F. Peralta, J. Knowl. Manag. 16, 267 (2012)

24. O. Sunardi, J.H. Tjakraatmadja, Proceeding of the $13^{\text {th }}$ ICDSI-APDSI (2013)

25. C. Syverson, Global Econ. Dev. (2016)

26. A.B. Bouazza, D. Ardjouman, O. Abada, Am. Int. J. Soc. Sci. 4, 101 (2015)

27. S. Kim, Contemp. Econ. Pol. 34, 572 (2016) 